\title{
Radiation Enhanced Porosity and Roughness of Biomaterials
}
A. L. Evelyn ${ }^{1}$, M. G. Rodrigues ${ }^{2}$, D. Ila ${ }^{1}$, R. L. Zimmerman ${ }^{1}$, D. B. Poker ${ }^{3}$, D. K. Hensley ${ }^{3}$
${ }^{1}$ Center For Irradiation of Materials, Alabama A\&M University, Normal, AL 35762, USA
${ }^{2}$ University of São Paulo, DFM-FFCLRP, Ribeirão Preto, SP 14040-901, Brazil
${ }^{3}$ Oak Ridge National Laboratory, SMAC, Oak Ridge, TN 37831, USA

\section{ABSTRACT}

Glassy Polymeric Carbon (GPC), made from cured phenolic resins, is sufficiently chemically inert and biocompatible that it is suitable for medical applications, such as heart valves and other prosthetic devices. We have used energetic ion bombardment of the partially and fully cured precursor phenolic resins to enhance biological cell/tissue growth on, and to increase tissue adhesion to, prosthetic devices made from GPC. GPC samples were bombarded with energetic ions to $10 \mathrm{MeV}$. The surface topography and increased surface roughness was observed using optical microscopy and atomic force microscopy (AFM). The increased porosity was measured by introducing lithium from a molten $\mathrm{LiCl}$ salt into the GPC and using $(\mathrm{p}, \alpha)$ nuclear reaction analysis (NRA) to measure the concentration of Li retention in the modified GPC. The NRA measurements of increased pore availability were correlated with the observations of increased surface roughness.

\section{INTRODUCTION}

Glassy Polymeric Carbon (GPC) is made from cured phenolic resins (resol), Fig. 1.a, in an inert environment. After curing at $60^{\circ} \mathrm{C}$, Fig. 1.b, the resin is pyrolyzed at low temperature rates to avoid changing shape or disruption due to volatile decomposition products (1). Heat treatment to $550^{\circ} \mathrm{C}$ produces a conducting material due to hydrogen release and conjugation of the aromatic rings forming graphene planes in random arrangement (2). For heat treatment at $650^{\circ} \mathrm{C}$, the material still presents open porosity due to space between the ribbons. Further heat treatment to $1000^{\circ} \mathrm{C}$ the GPC pores remain but progressively close, reducing permeability as the graphitic planes aggregate themselves to form the final structure of the GPC, Fig. 1.c, (3). The final GPC structure is as random graphene planes shown in Fig. 2 and the material appears dark, hard and vitreous. Its density (1.45) is significantly lower than that of graphite from which one may deduce a relative pore volume of about $35 \%$.

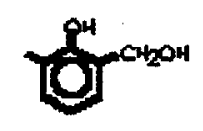

A)

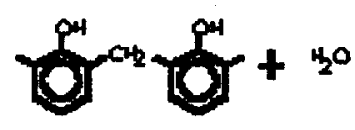

B)

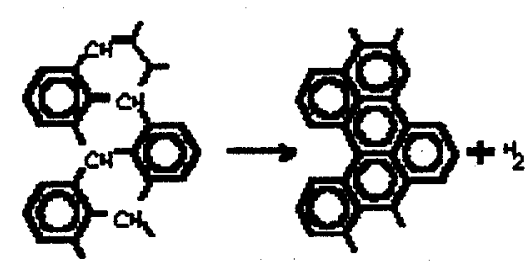

C)

Fig. 1: Structures of a) resol, b) the polymer which forms at $130^{\circ} \mathrm{C}$ and c) a graphene plane as heat treatment is increased beyond $700^{\circ} \mathrm{C}$.

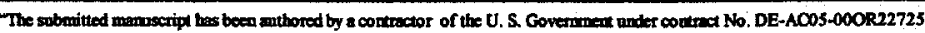

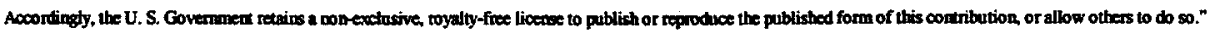




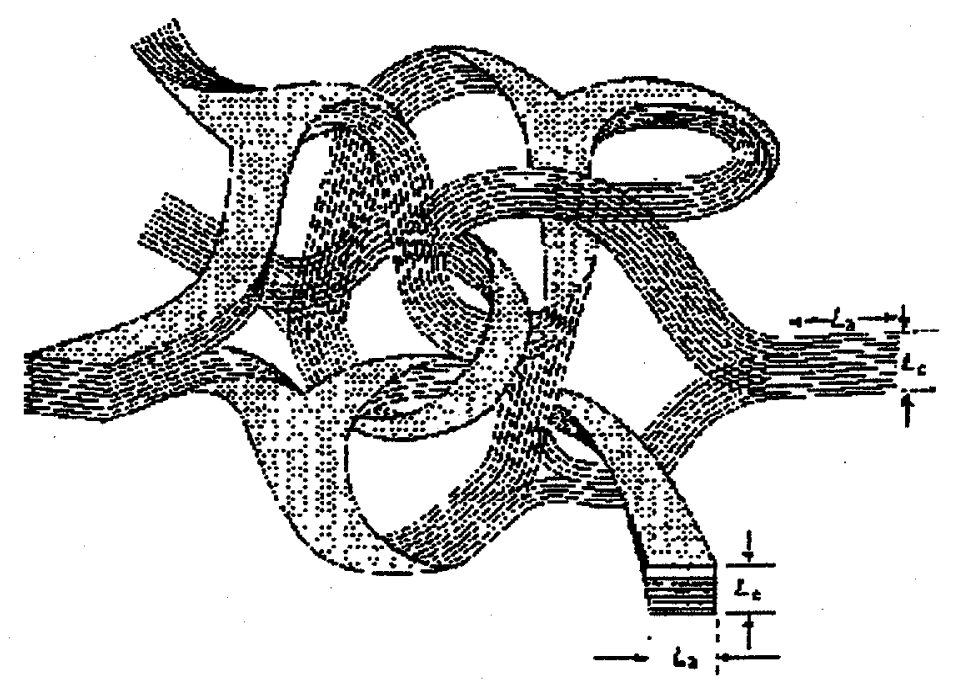

Fig. 2: GPC structure, according to Ref. [1]. $\mathrm{L}_{\mathrm{A}}$ and $\mathrm{L}_{\mathrm{C}}$ are of the order of $10 \mathrm{~nm}$ and the pores are closed such that the material is completely impermeable.

This work has been motivated because GPC is increasingly used in medicine in the manufacture of heart valves due to its inertness and biocompatibility $(4,5)$. GPC replacement artifacts still present some dysfunction or thromboembolic problems as a result of low adhesion at the interface between its surface and the biological tissue $(6,7)$. Thromboresistence can be achieved by treatment of the surface of the biomaterial, making it rough. The roughness can increase the adherence of the endothelialized tissue contacting the prosthetic component surface. The texture desired for this medical purpose should be a profile of cavities in the surface whose dimensions are sufficient (about 10-20 $\mu \mathrm{m}$ ) to allow formation of tissue that adheres to the material surface. Ion bombardment was used to increase the roughness of GPC samples.

\section{MATERIALS AND METHODS}

The samples from phenolic resin were cured following the process described in Ref. (8).

Then, the samples were pyrolysed at $700^{\circ} \mathrm{C}$ and $1500^{\circ} \mathrm{C}$. The heating rates follow (8): from $20^{\circ} \mathrm{C}$ to $100^{\circ} \mathrm{C}, 20^{\circ} \mathrm{C} / \mathrm{h}$; from $100^{\circ} \mathrm{C}$ to $200^{\circ} \mathrm{C}, 7^{\circ} \mathrm{C} / \mathrm{h}$; from $200^{\circ} \mathrm{C}$ to $500^{\circ} \mathrm{C}, 2^{\circ} \mathrm{C} / \mathrm{h}$; from $500^{\circ} \mathrm{C}$ to $700^{\circ} \mathrm{C}, 3^{\circ} \mathrm{C} / \mathrm{h}$; from $650^{\circ} \mathrm{C}$ to $1500^{\circ} \mathrm{C}, 40^{\circ} \mathrm{C} / \mathrm{h}$.

Individual samples were bombarded with ions and their range as follows (fluence in units of ions $\left./ \mathrm{cm}^{2}\right)(8)$ :

Oxygen, $8 \mathrm{MeV}, 1.0,2.8$ and $10 \times 10^{13}, 6.77 \mu \mathrm{m}$, Carbon, $6 \mathrm{MeV}, 3.0,10$ and $30 \times 10^{13}, 6.75 \mu \mathrm{m}$, Silicon, $5 \mathrm{MeV}, 0.5,3.4$ and $10 \times 10^{13}, 4.14 \mu \mathrm{m}$, Gold, $10 \mathrm{MeV}, 1.0,10$ and $100 \times 10^{14}, 2.84 \mu \mathrm{m}$.

The roughness of the samples was measured with a Surface Profiler Non-Contact TOPO-3D. Bombarded and unbombarded regions of the samples were compared. The texture was observed with Atom Force Microscopy. The results were correlated with available porosity measured by 
lithium absorption in other samples after bombardment with the same ions, energies and fluences. The lithium absorption was carried out at $700^{\circ} \mathrm{C}$ in a molten $99.6 \%$ lithium chloride bath for a duration of one hour. The near surface concentration profile of lithium in these samples was measured by Nuclear Reaction Analysis (RNA). Alpha particles from the Li(p, 2 $\alpha)(\mathrm{Q}=17.256$ $\mathrm{MeV})$ reaction were observed from the surface to a depth of about $10 \mu \mathrm{m}$ below the surface of the GPC, beyond which the energy of the protons is insufficient to react with lithium. A 100 nanoampere $1.03 \mathrm{MeV}$ proton beam and a silicon surface detector, at a back angle of $170^{\circ}$ were used to perform the NRA.

\section{RESULTS AND DISCUSSIONS}

Fig. 3 shows that the surfaces of all samples become rough after ion bombardment. Samples prepared at $700^{\circ} \mathrm{C}$ presented greater RMS roughness than for samples prepared at $1500^{\circ} \mathrm{C}$. This probably is due to GPC's hardness and purity, both of which increase with heat treatment temperatures. For all ions there is a specific fluence value for which the roughness tends to decrease as the fluence is increased.

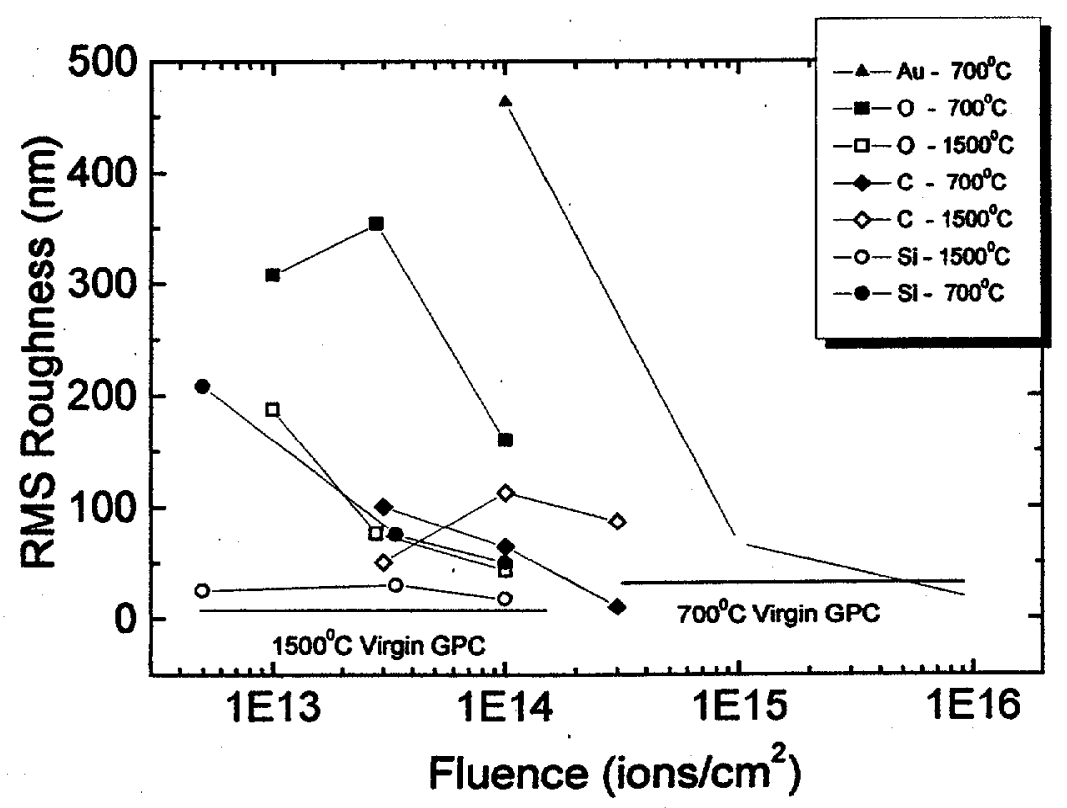

Fig. 3: RMS roughness of GPC as a function of fluence after bombardment with the ion shown. (See text for ion energies).

Fig. 4 shows the AFM surface profile of the $700^{\circ} \mathrm{C}$ GPC sample without any bombardment to be compared with the texture obtained for the oxygen bombarded sample as is shown in Fig. 5. For these samples AFM showed a specific texture, which presented $40 \mu \mathrm{m}$ width regions, separated by $10-30 \mu \mathrm{m}$ gaps. For fluences higher than $2.8 \times 10^{13}$ oxygen ions $/ \mathrm{cm}^{2}$ the roughness decreased. 


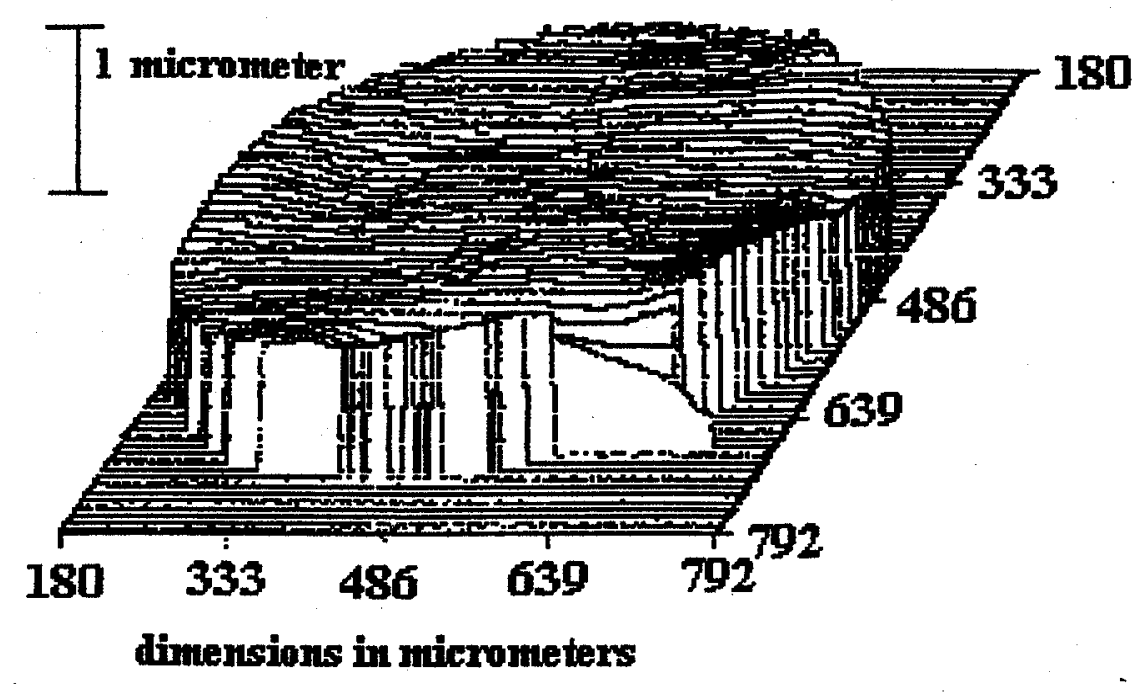

Fig. 4: $700^{\circ} \mathrm{C}$ GPC before ion bombardment.

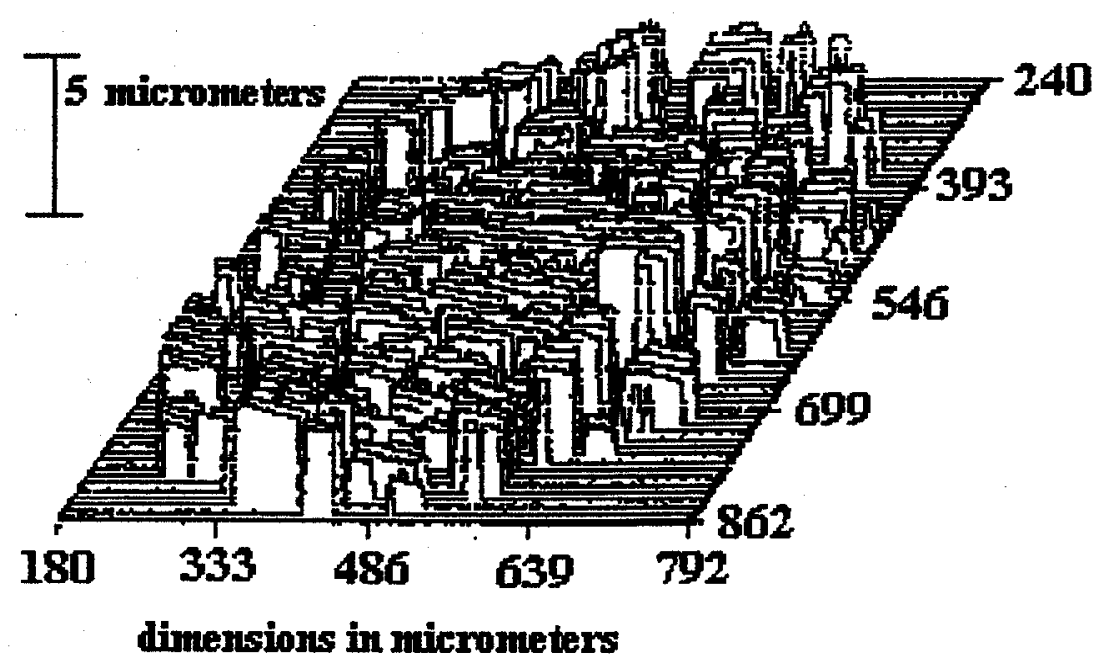

Fig. 5: $700^{\circ} \mathrm{C} \mathrm{GPC}$ after bombardment with $8 \mathrm{MeV}$ oxygen ions at a fluence of $2.8 \times 10^{13}$ ions $/ \mathrm{cm}^{2}$.

Fig. 6 shows the lithium concentration from the NRA that has diffused into the near surface region of GPC heat treated to temperatures of $700^{\circ} \mathrm{C}$ and $1500^{\circ} \mathrm{C}$ in a molten $\mathrm{LiCl}$ bath at $700^{\circ} \mathrm{C}$. This is a direct measurement of the available porosity. NRA studies showed that lithium diffusion into GPC is enhanced even beyond the range of bombarding ions. The results of Fig. 6 show that ion bombardment improved the lithium absorption relative to the GPC without any bombardment. Similar to roughness results, the absorption was bigger for samples prepared at $700^{\circ} \mathrm{C}$. For lithium absorption it was observed a dependence of the enhancement of diffusion on the fluence, saturating or decreasing at high fluences.

Both roughness and available porosity increase with ion bombardment for low fluences, then saturate or decrease at higher fluences. Evidently, ion bombardment beyond a critical fluence causes densification and polishing of the initially rough, porous surface. 


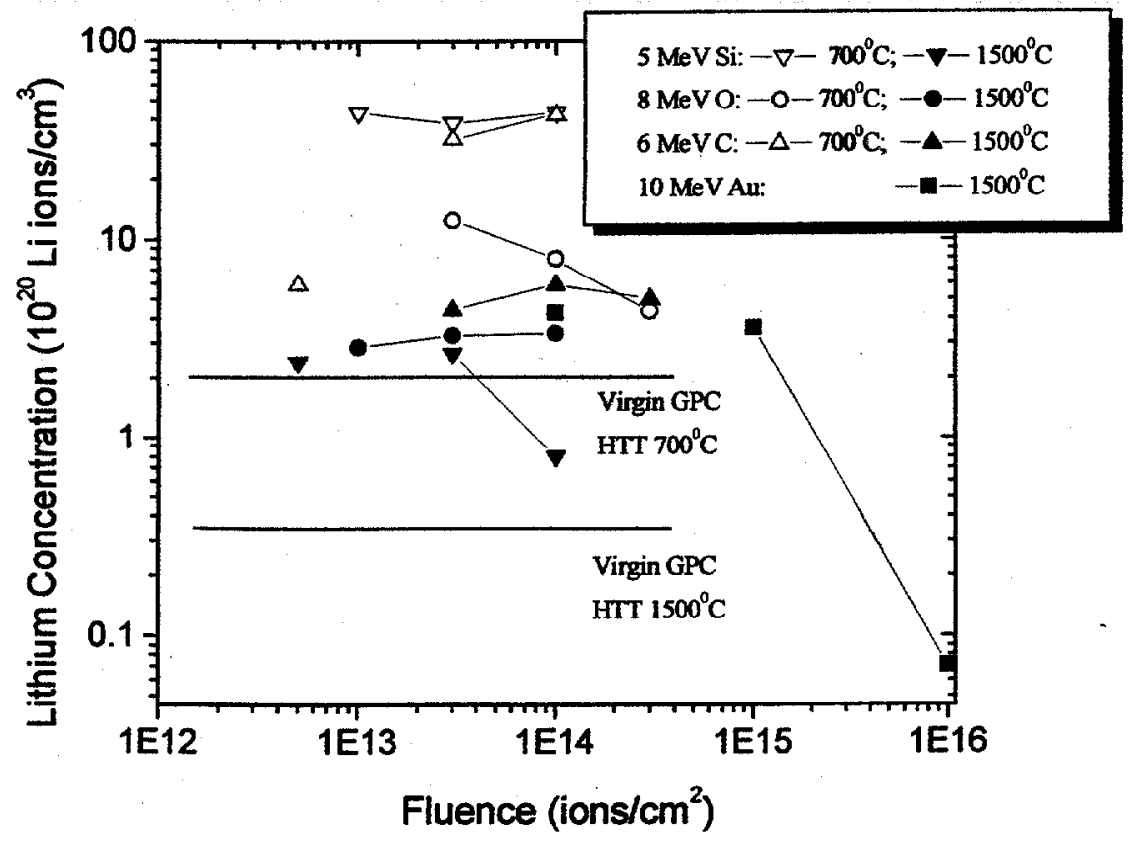

Fig. 6: Lithium concentration into near surface region of GPC heat-treated to temperatures of $700^{\circ} \mathrm{C}$ and $1500^{\circ} \mathrm{C}$ in a molten $\mathrm{LiCl}$ bath at $700^{\circ} \mathrm{C}$.

The value of fluence at which maximum roughness can be achieved has a dependence on the pore density and the size of the ion used for the bombardment. The hypothesis here is that ion bombardment improves the permeability by opening the pores, making them interconnected. If the fluence is higher than the pore density of the material near the surface, ion bombardment makes the pores unavailable $(9,10)$.

\section{CONCLUSIONS}

Our results showed that ion bombardment can be used for the production of GPC artifacts with textured surfaces, which can enhance the biocompatibility of biomaterials. The bombardment improved the absorption of lithium which indicates that a significant transfer of energy to the recoil carbon atoms, as well as the residual positive charge near the primary ion track, leads us to expect that damage along the track might cause neighboring pores to connect. As the diffusion is observed beyond the depth of implantation, the lithium absorption can be correlated with roughness of the surface as well as the available porosity.

\section{ACKNOWLEDGMENTS}

The authors would like to thank Prof.First Name Li from The University of Alabama in Huntsville (UAH), USA. This work was partially supported by FAPESP - São Paulo/Brazil, the CIM, Alabama A\&M University, Alabama/USA, and Oak Ridge National Laboratory, managed by UTBattelle, LLC, for the U.S. Department of Energy under contract DE-AC05-00OR22725. 


\section{REFERENCES}

1. Jenkins G. M. and Kawamura K., Polymeric Carbons-Carbons Fiber, Cambridge, Cambridge University Press, 1976.

2. Maleki H., Holland L. R., Jenkins G. M., Zimmerman, R. L., J. Mater. Res., 11, No. 9, (1996) 2368.

3. Maleki, H., Ila, D., Jenkins, G. M., Zimmerman, R. L., Evelyn, A. L., Mat. Res. Soc. Symp. Proc., 371, (1995) 0443.

4. Jenkins G. M., Grigson, C. J., J. Biomed. Mat. Res., 13, (1979) 371-394.

5. Jenkins G. M., Ila, D., Maleki, H., Mat. Res. Soc. Symp. Proc., 394, (1995) 181.

6. Braunwald, N. S., Bonchek, L. I., J. Thoracic \& Cardiovasc. Surg., 54, No 5 (1967).

7. Magalhaes, H. P., Machado, A. L., Raoul, A. J., Soutelo Filho, A. F., Vaidergorn, J., dos Santos, J. A., Rev. Bras. Cir. Cardiovasc., 11, No 4, (1996) 273.

8. Zimmerman, R. L., Ila, D., Jenkins, G. M., Maleki, H., Poker, D. B., Nucl. Instr. and Meth. in Phys. Res., B 106, (1995) 550.

9. Ila, D., Jenkins, G. M., Zimmerman, R. L., Evelyn, A. L., Mat. Res. Soc. Symp. Proc., 331, (1994) 281.

10. Zimmerman, R. L., Ila, D., Poker, D. B., Withrow, S. P., Application of Accelerators in Research and Industry, Duggan \& Morgan, New York, 1996, p957. 